\title{
«Ketamina y midazolam por vía intramuscular en el tratamiento de quemaduras en zona de guerra»
}

\section{Sr. Director:}

La ketamina y el midazolam son fármacos anestésicos de elección en medios austeros debido a sus mecanismos de acción, perfiles farmacocinéticos y farmacodinámicos ${ }^{1,2}$. La asociación de ketamina y midazolam es una alternativa útil a la de opioide y benzodiacepina. Su empleo se preconiza para disminuir la agitación en la fase de recuperación posterior a la sedación inducida por la ketamina. Han sido empleados profusamente en diferentes conflictos del siglo $\mathrm{XX}^{3,4}$.

Se exponen 2 casos clínicos de analgesia multimodal empleando ketamina y midazolam, para el tratamiento de pacientes que han sufrido quemaduras de origen bélico. Estos heridos fueron tratados por equipos de sanidad militar españoles en las instalaciones sanitarias desplegadas en la provincia afgana de Badghis durante septiembre de 2012.

\section{CASO 1}

Paciente de 3 años $(94 \mathrm{~cm}, 10 \mathrm{Kg}$ ), niña, afgana, con signos de desnutrición, que presentaba quemaduras de segundo grado en región anterior y posterior muslo derecho (figura 1), flanco derecho y mesogastrio ( $25 \%$ de superficie corporal quemada) secundaria a una explosión desde hace 4 días. Se aplicó tratamiento tópico que resultó ineficaz. Debido a la evolución tórpida de la lesión, se decidió desbridamiento mecánico local y aplicación de sulfadiacina argéntica y apósito Tulgrasum ${ }^{\circledR}$ cicatrizante impregnado de antibiótico (bacitracina-zinc, neomicina, sulfato de polimixina B). Para permitir el procedimiento se administró de forma previa midazolam (1 mg i.m) y a los 5 minutos ketamina $(60 \mathrm{mg}$ i.m). Se consiguió analgesia (grado 0 según la escala verbal del dolor) y sedación a los 10 minutos (puntuación 4 en

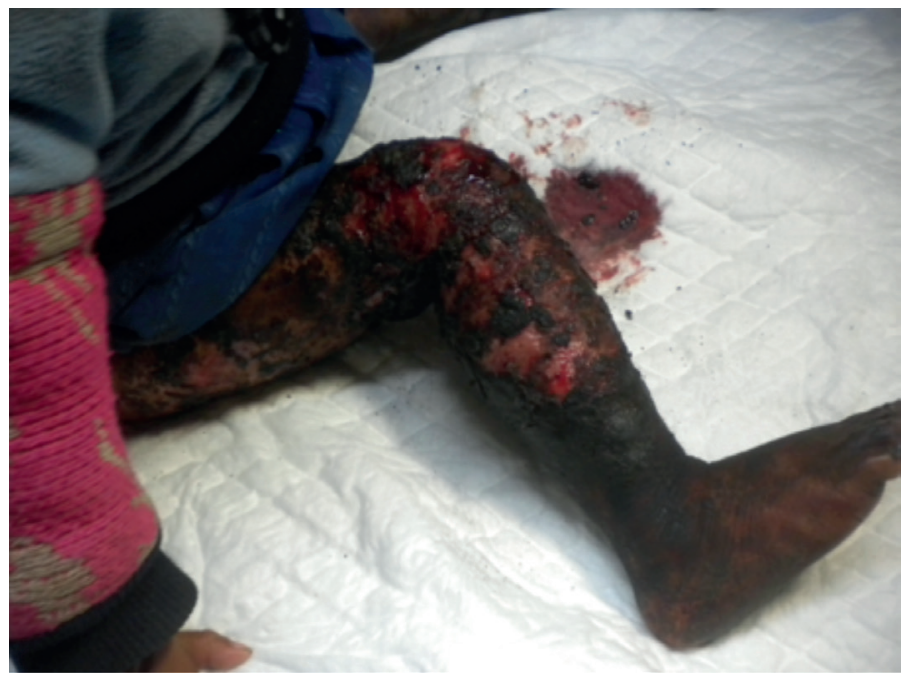

Figura 1. Quemadura de segundo grado en pierna de caso 1. escala Ramsay), permitiendo realizar la cura sin incidencias durante 22 minutos. El paciente recuperó sensibilidad y vigilia a los 120 minutos de la administración del tratamiento. El grado de amnesia del procedimiento quirúrgico valorado por la escala de Korttila y Linnolia fue total.

\section{CASO 2}

Paciente de 22 años $(178 \mathrm{~cm}, 70 \mathrm{Kg})$, varón, militar afgano, que presentaba quemadura de segundo grado en la cara interna del antebrazo y brazo derecho (7\% de superficie corporal quemada) secundaria a una explosión desde hace 72 horas. Se aplicó tratamiento tópico que resultó ineficaz. Debido a la evolución tórpida de la lesión, se decidió desbridamiento mecánico local y aplicación de sulfadiacina argéntica y apósito Tulgrasum ${ }^{\circledR}$ cicatrizante impregnado de antibiótico (bacitracina-zinc, neomicina, sulfato de polimixina B). Para permitir el procedimiento se administró de forma previa midazolam ( $3 \mathrm{mg}$ i.m) y a los 5 minutos ketamina (200 mg i.m). Se consiguió analgesia (grado 1 según la escala verbal del dolor) y sedación a los 12 minutos (puntuación 3 en escala Ramsay), permitiendo realizar la cura sin incidencias durante 16 minutos. El paciente recuperó sensibilidad y vigilia a los 55 minutos de la administración del tratamiento. El grado de amnesia del procedimiento quirúrgico valorado por la escala de Korttila y Linnolia fue total.

Ambos casos presentaron una evolución favorable sin efectos adversos durante curas posteriores.

En zona de combate, es frecuente encontrar heridos que presentan quemaduras de distinto grado y extensión debido principalmente al empleo de artefactos explosivos por parte de los contendientes. En un estudio realizado sobre 256 heridos por arma de fuego o por artefacto explosivo improvisado atendidos en el hospital militar español de Herat (Afganistán) entre 2005 y 2008, se describe que $23(9 \%)$ sufrieron quemaduras 5 .

A dosis adecuadas el empleo de ketamina y midazolam consigue un adecuado estado analgésico, hipnótico y ansiolítico con una estabilidad hemodinámica notable y un mantenimiento espontáneo de la función respiratoria. Además, la posibilidad de emplear ambos fármacos por vía intramuscular minimiza ostensiblemente los requerimientos logísticos necesarios en cada paciente. La sedación con midazolam debe ser previa a la administración de la ketamina, ya que en caso contrario podría producirse una marcada estimulación cardiovascular y presentarse desagradables reacciones psicomiméticas al despertar. Así mismo se podría añadir atropina para minimizar la posible aparición de sialorrea, aunque en ninguno de los dos casos fue administrada ni apareció un aumento de secreciones en estos pacientes. Dichas características hacen estos fármacos de elección para la anestesia en ambientes austeros, como es el de la guerra de Afganistán. 
1. Dawes RJ, Mellor A. Pre-hospital anaesthesia. J R Army Med Corps Cte. Médico 2011;156 (4): 289-94

2. Mion G. Ketamina. EMC-Anestesia-Reanimación 2012;38(4):1-13.

3. Mercer SJ. The drug of war, a historical review of the use of ketamine in mili-

Sergio Castillejo Pérez
Cap. Médico tary conflicts. J Royal Naval Medical Service 2009; 95(3): 145-50.

Javier de las Heras Díez

4. Black IH, McManus J. Pain management in current combat operations. Pre-

Cap. Médico hospital Emergency Care 2009; 13(2): 223-7.

5. Navarro R, Hernández A, Gutiérrez C, Bartolomé E, Lam D, Gilsanz F. Gunshot and improvised explosive casualties: a report from the spanish Role 2 medical facility in Herat, Afghanistan. Mil Med 2012;177:326-32.

Servicio de Anestesiología y Reanimación

Rafael Tamburri Bariain

Cte. Médico

Servicio de Traumatología

Hospital Central de la Defensa «Gómez Ulla». Madrid 